\title{
CoIPuS, a new Multi-Isotope Plutonium Standard for Accelerator Mass Spectrometry
}

Björn-Alexander Dittmann ${ }^{a, b}$, Raffaele Buompane ${ }^{c}$, Elena Chamizo ${ }^{d}$, Marcus Christl ${ }^{e}$, Alfred Dewald ${ }^{f}$, Tibor Dunaib, Claus Feuerstein ${ }^{f}$, Keith Fifield ${ }^{g}$, Michaela Fröhlich $^{g}$, Stefan Heinze, Fabio Marzaiolic, Carsten Münker ${ }^{b}$, Antonio Petraglia ${ }^{c}$, Carmina Sirignanoc ${ }^{c}$ Erik Strub $^{a, h}$, Hans- $^{-}$ Arno Synal ${ }^{2}$, Filippo Terrasi ${ }^{i}$, Stephen Tims ${ }^{g}$, Anton Wallner ${ }^{g}$

aDivision of Nuclear Chemisty, University of Cologne, Zülpicher Str. 45, 50674 Cologne, Germany, corresponding author

'blnstitute of Geology and Mineralogy, University of Cologne, Zülpicher Str. 49b, 50674 Cologne, Germany

${ }^{\circ}$ Centre for Isotopic Research on the Cultural and Environmental Heritage, University Luigi Vanvitelli, Viale Lincoln 5, 81100 Caserta, Italy

${ }^{d}$ Centro Nacional de Aceleradores (Universidad de Sevilla, Consejo Superior de Investigaciones Científicas, Junta de Andalucía). Thomas Alva Edison 7, 41092, Seville, Spain

'Laboratory of Ion Beam Physics, ETH Zurich, Otto-Stern-Weg 5, 8093 Zurich, Switzerland 'Institute of Nuclear Physics, University of Cologne, Zülpicher Str. 77, 50937 Cologne, Germany

פDepartment of Nuclear Physics, Research School of Physics \& Engineering, Australian National University, Canberra ACT 2601, Australia

hForschungszentrum Jülich GmbH, INM-5, 52425 Jülich, Germany

Keywords: AMS, Plutonium isotopic standard, consensus value, MC-ICPMS

\begin{abstract}
A new multi-isotope plutonium standard for isotopic ratio measurements with Accelerator Mass Spectrometry (AMS) was created by gravimetric mixing of different single-isotope standards provided by IRMM (Pu-239, Pu-240, Pu-242, Pu-244). This standard material has been measured at the AMS facilities at Canberra (Australia), Cologne (Germany), Caserta (Italy), Sevilla (Spain) and Zurich (Switzerland). Additionally, the material was characterized using a Neptune MC-ICPMS (multi-collector inductively coupled plasma mass spectrometry) at the joint Cologne-Bonn isotope facility. The results of this laboratory intercomparison are presented and consensus values for the isotope compositions of the standard material are proposed.
\end{abstract}

\section{Introduction}


Accelerator Mass Spectrometry (AMS) is commonly applied to the plutonium isotopes ${ }^{239} \mathrm{Pu}$, ${ }^{240} \mathrm{Pu},{ }^{241} \mathrm{Pu}$ and ${ }^{242} \mathrm{Pu}$. Another isotope, ${ }^{238} \mathrm{Pu}$, is also of interest in environmental applications, but is difficult to measure by Accelerator Mass Spectrometry (AMS) due to the interference from isobaric ${ }^{238} \mathrm{U}$. Plutonium measurements by AMS are frequently used to identify the sources of observed Pu contaminations in various contexts (see e.g. [1], [2]). Therefore, reliable standards with a well-known isotope composition are required for AMS calibration and normalization.

Currently, two established multi-isotope $\mathrm{Pu}$ standards have been employed for the normalization of Pu AMS measurements; i) the primary standard UKAEA No. UK 5/92138 [3] and ii) a secondary standard prepared at the Centro Nacional de Aceleradores (CNA) [4]. Due to the growing numbers of Pu AMS applications, the stocks of the existing primary standard are declining and this material is not available any more for new AMS facilities. Anticipating this limitation, the secondary CNA standard was produced in 2009 and later calibrated against the UKAEA primary standard [5]. It was originally intended for in-house measurements, so it was not produced with the aim of being used at different AMS labs and it was calibrated for the $\mathrm{Pu}$ isotopes ${ }^{239} \mathrm{Pu},{ }^{240} \mathrm{Pu}$ and ${ }^{242} \mathrm{Pu}$, but never for ${ }^{244} \mathrm{Pu}$.

However, over the last few years, ${ }^{244} \mathrm{Pu}$ came into the focus of research activities in the field of astrophysics [6][7][8]. Therefore, a new multi-isotope standard, covering the AMS relevant mass range of $\mathrm{Pu}$ isotopes from 239 to 244 , has been prepared. It was characterized in a first round-robin exercise by the AMS laboratories at the University of Cologne, the ETH Zurich, and at the Australian National University, Canberra. The preliminary results of the measured isotope composition showed good agreement with the gravimetrically determined nominal ratios [9]. Additional measurements of this Pu standard have now been performed, including two additional AMS facilities, the CNA Seville, Spain [10] and University Luigi Vanvitelli - Centre for Isotopic Research on the Cultural and Environmental Heritage (CIRCE), Italy [11] and a MC-ICPMS (Multi-Collector Inductively Coupled Plasma Mass Spectrometry) measurement (University of Cologne, Germany). The goal of these measurements was

i. to establish a new standard material containing the isotopes ${ }^{239} \mathrm{Pu},{ }^{240} \mathrm{Pu},{ }^{242} \mathrm{Pu}$ and ${ }^{244} \mathrm{Pu}$ like the original UKAEA standard,

ii. to characterize this standard at least as precisely as the CNA standard, for which the uncertainties of the given isotope ratios are in the range of 2.1 to $2.4 \%(1 \sigma)$, and,

iii. to obtain sufficient reference material for the next decades, i.e. an amount that is sufficient for more than $100^{\prime} 000$ single measurements, .i.e. $>10^{15}$ atoms per isotope. 
In this paper, we report and analyze the results of the AMS round-robin exercise and the MCICPMS measurements. Finally, we propose a consensus value (CV) in order to establish the material as a new Pu standard material.

\section{Experimental and Results}

\subsection{Gravimetric mixing}

The isotopically-enriched plutonium CRMs (certified reference materials) IRMM-081a, IRMM083, IRMM-43, IRMM-42a have been obtained from JRC IRMM (Joint Research Centre Institute for Reference Materials and Measurements). A new multi-isotope plutonium standard, containing the isotopes ${ }^{239,240,242,244} \mathrm{Pu}$ was prepared at the University of Cologne by gravimetric mixing and dilution of these CRMs. The estimated uncertainty of this gravimetric approach is low with respect to the uncertainty of the certified isotopic ratios of the used Pu CRMs. For calculation of the isotope composition, the certified values of all minor $\mathrm{Pu}$ isotopes of each CRM have been taken into account [9]. The calculated isotope composition of the new standard material is given in Table 1.

Table 1: Pu isotope composition of the new standard as calculated from the gravimetric mixing (1 $\sigma$ uncertainties).

\begin{tabular}{|l|l|l|l|l|}
\hline & ${ }^{239} \mathrm{Pu} /{ }^{242} \mathrm{Pu}$ & ${ }^{240} \mathrm{Pu} /{ }^{242} \mathrm{Pu}$ & ${ }^{240} \mathrm{Pu} /{ }^{239} \mathrm{Pu}$ & ${ }^{244} \mathrm{Pu} /{ }^{242} \mathrm{Pu}$ \\
\hline gravimetric & $1.0508 \pm 0.0033$ & $1.0582 \pm 0.0034$ & $1.0070 \pm 0.0010$ & $0.1038 \pm 0.0004$ \\
\hline
\end{tabular}

Although it was assured that these calculated compositions are very precise, the goal was to establish a consensus value not only based on this calculated value, but also on actual results of characterizing measurements of the standard material. Therefore, the isotope composition was verified by a round-robin between five AMS facilities, as well as by an independent measurement utilizing MC-ICPMS.

Detailed Information concerning the source material for the multi-isotope Pu standard, its subsequent preparation and the target preparation procedure for AMS measurements can be found in [9].

\subsection{MC-ICPMS measurements}

In order to determine the isotope composition of the Pu-standard by MC-ICPMS, two different sample solutions were measured with $\mathrm{Pu}$ isotope concentrations of approximately $5 \mathrm{pg} \cdot \mathrm{g}^{-1}$ for the main isotopes $\left({ }^{239,240,242} \mathrm{Pu}\right)$ and $50 \mathrm{pg} \mathrm{g}^{-1}$, respectively. For the sample solution with a weight equivalent of $50 \mathrm{ppt}$, the Pu-standard working solution was used as prepared [9]. For 
the preparation of the sample solution with a weight equivalent of $5 \mathrm{ppt}, 2.3517 \mathrm{~g}$ of this $\mathrm{Pu}$ standard working solution were transferred in a $30 \mathrm{~mL}$ Teflon vial, evaporated to dryness and re-dissolved in $20.1872 \mathrm{~g} 0.3 \mathrm{M} \mathrm{HNO}_{3}$. Based on the weighings, the resulting effective $\mathrm{Pu}$ weight equivalents for the main $\mathrm{Pu}$ isotopes in the two sample solutions were $\approx 4.5 \mathrm{ppt}$ (4.82 ppt ${ }^{239} \mathrm{Pu}$. $4.87 \mathrm{ppt}{ }^{240} \mathrm{Pu}, 4.63 \mathrm{ppt}{ }^{242} \mathrm{Pu}$, and $\left.0.486 \mathrm{ppt}{ }^{244} \mathrm{Pu}\right)$ and $\approx 45 \mathrm{ppt}\left(46.2 \mathrm{ppt}{ }^{239} \mathrm{Pu}\right.$. $46.7 \mathrm{ppt}{ }^{240} \mathrm{Pu}, 44.2 \mathrm{ppt}{ }^{242} \mathrm{Pu}$, and $4.66 \mathrm{ppt}{ }^{244} \mathrm{Pu}$ ), respectively.

The Pu isotope data were acquired using a NEPTUNE MC-ICPMS (ThermoFisher Scientific) at the University of Cologne. Sample introduction to the argon plasma was via a desolvating nebulizer system (Aridus II, Cetac), using a 100 $\mu$ PFA nebulizer. All measurements were performed at low-resolution $(\mathrm{m} / \Delta \mathrm{m}=400)$ in static mode. For optimization and tuning of the machine, as well as to correct for the mass discrimination during the measurements, all $\mathrm{Pu}$ measured solutions were spiked with a 5 ppb natural U standard (CRM 112-A, New Brunswick Laboratory, Argonne, IL, USA). A value of $137.837(15)$ for the ${ }^{238} \mathrm{U} /{ }^{235} \mathrm{U}$ isotope ratio was used for mass bias correction [12] employing the exponential law. Both $U$ and $\mathrm{Pu}$ isotopes were measured simultaneously in Faraday cups employing $10^{11} \Omega$ and $10^{12} \Omega$ amplifiers, yielding typical signals of around $30 \mathrm{mV}$ per $\mathrm{Pu}$ isotope. The typical operating parameters and the Faraday detector block setup are given in Table 2 and Table 3. Precision, in terms of a relative standard deviation, of the measurements was based on the number of measurement cycles during each sample analysis (see supplemental data). From a comparison of data obtained measuring the $45 \mathrm{ppt}$ and $4.5 \mathrm{ppt} \mathrm{Pu}$ solutions, respectively, it can be concluded that the possible contribution of ${ }^{238} \mathrm{U}$ tail and ${ }^{238} \mathrm{UH}^{+}$on the signal at mass 239 is smaller than the external reproducibility $( \pm 0.1 \%$, see Table 4$)$.

Table 2: Operating conditions used on the Neptune MC-ICPMS

\begin{tabular}{lr}
\hline Radiofrequency power & $1200 \mathrm{~W}$ \\
Acceleration voltage & $-2000 \mathrm{~V}$ \\
Sample cone & Nickel \\
Skimmer cone & Nickel X-Cone \\
Mass resolution & Low $(\mathrm{m} / \Delta \mathrm{m}=400)$ \\
Sampling mode & 20 \\
Integration time & $8,4 \mathrm{~s} \mathrm{per} \mathrm{cycle}$ \\
Sample flow rate & $0.1 \mathrm{~mL} \cdot \mathrm{min}^{-1}$ \\
Sample introduction system & Cetac Aridus II \\
Nebulizer & PFA-100 \\
Amplifier & $10^{12} \Omega, 10^{11} \Omega$ \\
\hline
\end{tabular}

Table 3: The setup of the Faraday collector block.

\begin{tabular}{l|c|c|c|c|c|c|c}
\multicolumn{1}{c}{ Cups } & $\mathrm{L} 3$ & $\mathrm{~L} 2$ & $\mathrm{~L} 1$ & Center & $\mathrm{H} 1$ & $\mathrm{H} 2$ & $\mathrm{H} 3$ \\
\hline Isotope & ${ }^{235} \mathrm{U}$ & ${ }^{238} \mathrm{U}$ & ${ }^{239} \mathrm{Pu}$ & ${ }^{240} \mathrm{Pu}$ & ${ }^{241} \mathrm{Pu}$ & ${ }^{242} \mathrm{Pu}$ & ${ }^{244} \mathrm{Pu}$ \\
Amplifier & $10^{12} \Omega$ & $10^{11} \Omega$ & $10^{11} \Omega$ & $10^{11} \Omega$ & $10^{11} \Omega$ & $10^{11} \Omega$ & $10^{12} \Omega$
\end{tabular}


The MC-ICPMS results are given in Table 4 (more detailed in supplemental data). The individual results show reproducibilities of ca. $\pm 0.05 \%(2 \sigma)$, external reproducibilities were estimates to $\pm 0.1 \%$ based on multiple measurement of standards at matching intensities.

Table 4: MC-ICPMS results. Note that the given reproducibilities are reported with $2 \sigma$ uncertainties while in the later discussion all values will be discussed based as $1 \sigma$ uncertainties

\begin{tabular}{|l|l|l|l|l|}
\hline & ${ }^{239} \mathrm{Pu} /{ }^{242} \mathrm{Pu}$ & ${ }^{240} \mathrm{Pu} /{ }^{242} \mathrm{Pu}$ & ${ }^{240} \mathrm{Pu} /{ }^{239} \mathrm{Pu}$ & ${ }^{24} \mathrm{Pu} /{ }^{242} \mathrm{Pu}$ \\
\hline MC-ICPMS mean & $1.055 \pm 0.001$ & $1.064 \pm 0.001$ & $1.012 \pm 0.001$ & $0.1040 \pm 0.0001$ \\
\hline
\end{tabular}

\subsection{AMS measurements}

Aliquots of the working solution of this material were shipped to the participating facilities. From this working solution, the preparation of the AMS targets were performed on-site (adding of $\mathrm{Fe}$ carrier, drying, calcinating, mixing with $\mathrm{Nb} 1: 4$, pressing). Detailed information about the AMS instrumentation of the participating facilities can be found in [5],[10],[11],[13], and [14], respectively.

In each AMS laboratory, 5-10 targets were characterized in 1-3 independent measurements. The measured ratios were normalized to the UKAEA standard, also measured by each of the laboratories. The composition of UK5/92138 was corrected for half-life. If a lab reported some technical problems during a measurement series, the reported results of this specific series were rejected and not considered for the calculation of the consensus value. In one case (AMS1 ), the results for ${ }^{244} \mathrm{Pu} /{ }^{242} \mathrm{Pu}$ were inconsistent showing deviations of $\pm 15 \%$ within the series and have been omitted. The results of the 7 (6) remaining measurement series are shown in Figure 1 and Table 2, respectively. For the calculation of the mean values, all AMS results were taken into account and weighted equally. Although the single series are partially deviating significantly, the mean ratios are in good agreement with the (nominal) values that were obtained from calculations of the gravimetric mixing. The given uncertainties were calculated as the standard errors of the mean. 


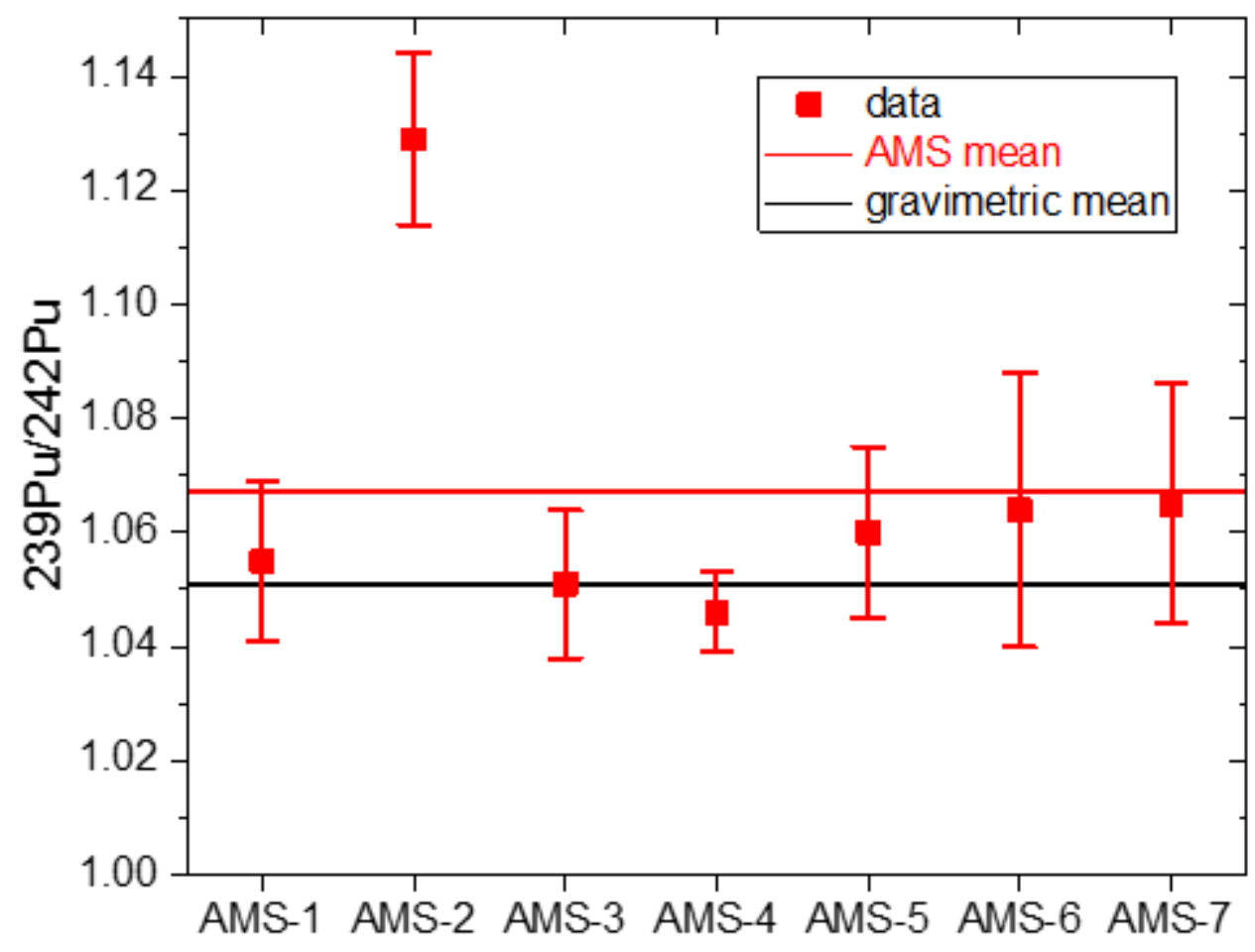

AMS result 


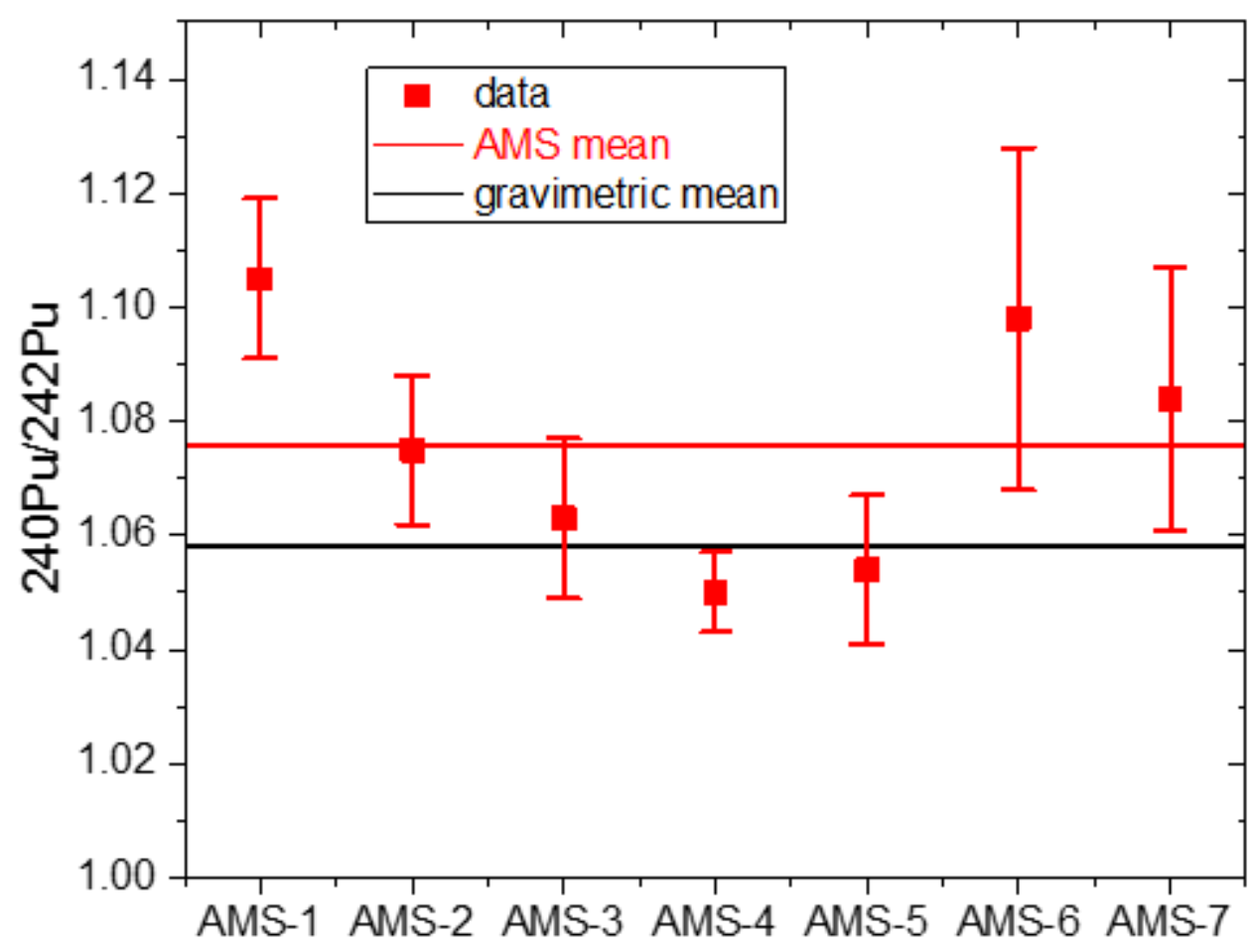

AMS result

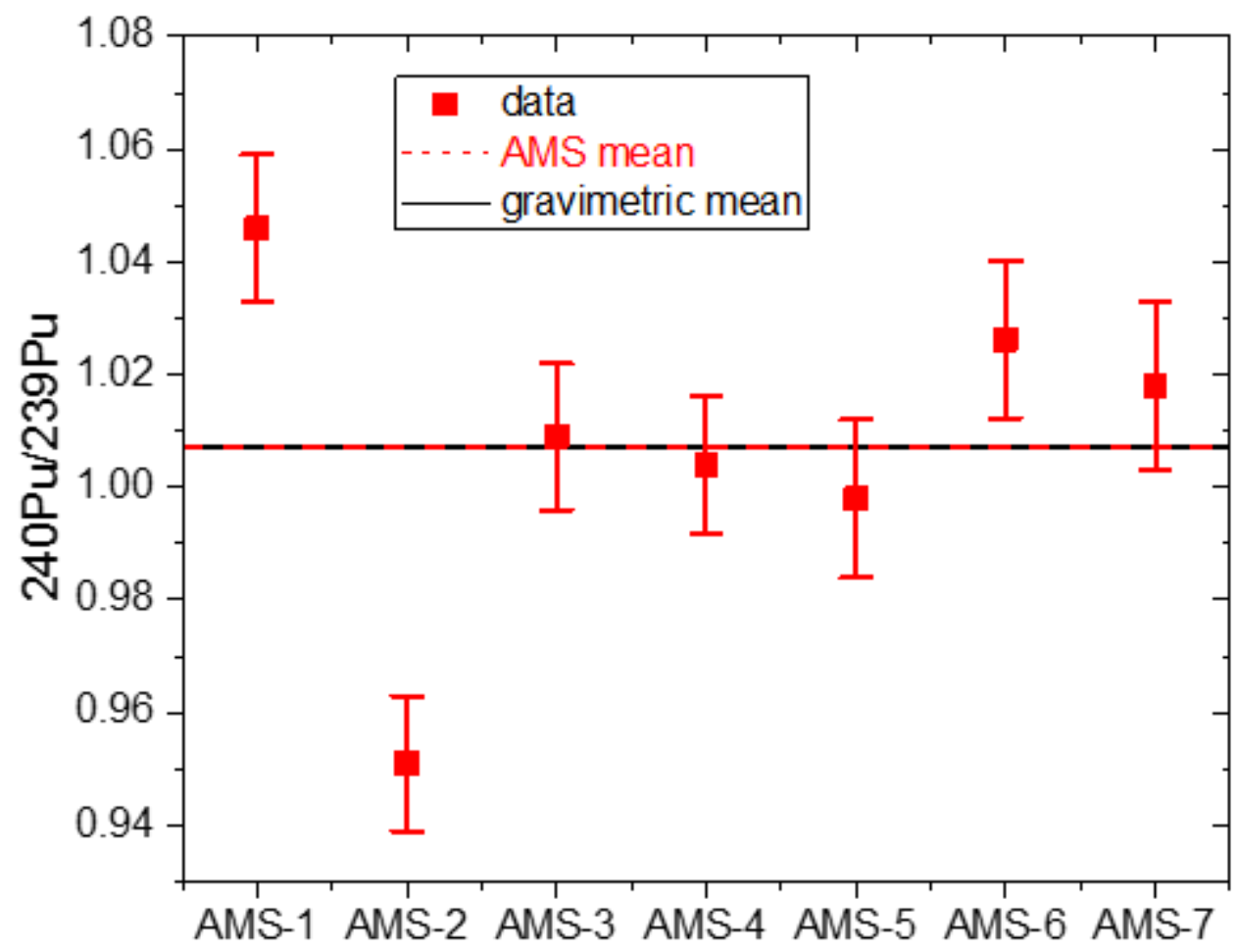

AMS result 


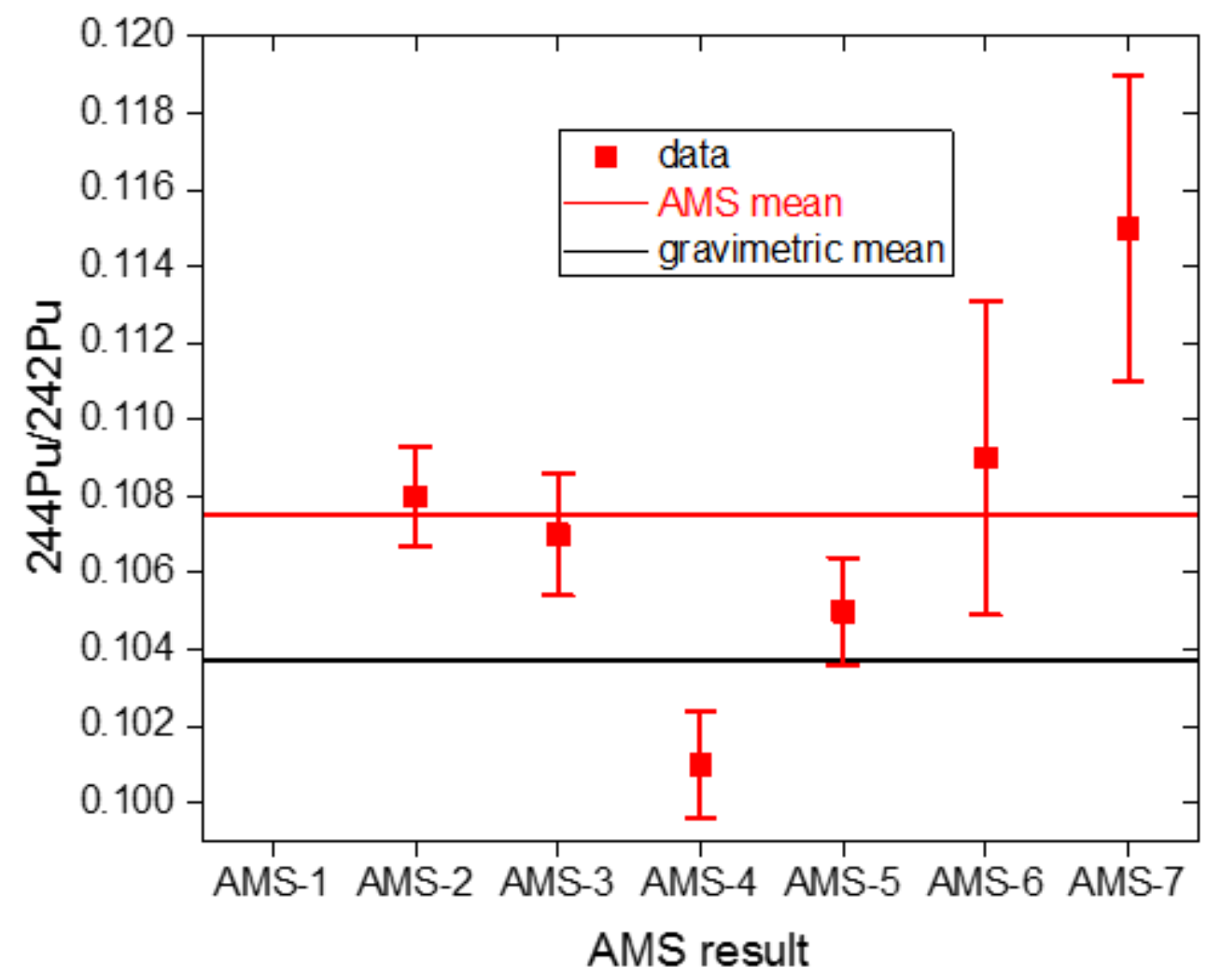

Figure 1: $\mathrm{Pu}$ isotope ratios of the new standard material as calculated from the AMS measurements ( $1 \sigma$ uncertainties). The mean values are in good agreement with the calculated ratios based on the gravimetric data.

Table 5: Pu isotope ratios of the new standard material as calculated from the AMS measurements. The individual measurement results are given with as the standard error of the mean; the uncertainty of the mean value was calculated as the standard deviation of the individual measurement from the mean.

\begin{tabular}{|l|l|l|l|l|}
\hline & ${ }^{239} \mathrm{Pu} /{ }^{242} \mathrm{Pu}$ & ${ }^{240} \mathrm{Pu} /{ }^{242} \mathrm{Pu}$ & ${ }^{240} \mathrm{Pu} /{ }^{239} \mathrm{Pu}$ & ${ }^{244} \mathrm{Pu} /{ }^{242} \mathrm{Pu}$ \\
\hline AMS-1 & $1.055 \pm 0.014$ & $1.105 \pm 0.014$ & $1.046 \pm 0.013$ & - \\
\hline AMS-2 & $1.129 \pm 0.015$ & $1.075 \pm 0.013$ & $0.951 \pm 0.012$ & $0.1078 \pm 0.0013$ \\
\hline AMS-3 & $1.051 \pm 0.013$ & $1.063 \pm 0.014$ & $1.009 \pm 0.013$ & $0.1073 \pm 0.0016$ \\
\hline AMS-4 & $1.046 \pm 0.007$ & $1.050 \pm 0.007$ & $1.004 \pm 0.012$ & $0.1013 \pm 0.0014$ \\
\hline AMS-5 & $1.060 \pm 0.015$ & $1.054 \pm 0.013$ & $0.998 \pm 0.014$ & $0.1049 \pm 0.0014$ \\
\hline AMS-6 & $1.064 \pm 0.024$ & $1.098 \pm 0.030$ & $1.026 \pm 0.014$ & $0.1089 \pm 0.0041$ \\
\hline AMS-7 & $1.065 \pm 0.021$ & $1.084 \pm 0.023$ & $1.018 \pm 0.015$ & $0.1150 \pm 0.0040$ \\
\hline mean & $\mathbf{1 . 0 6 7} \pm \mathbf{0 . 0 2 8}$ & $\mathbf{1 . 0 7 6} \pm \mathbf{0 . 0 2 1}$ & $\mathbf{1 . 0 0 7} \pm \mathbf{0 . 0 2 9}$ & $\mathbf{0 . 1 0 7 5} \pm \mathbf{0 . 0 0 4 5}$ \\
\hline
\end{tabular}




\section{Discussion}

\subsection{Comparison of the different methods}

When only comparing the gravimetric values with the MC-ICPMS results, the mean relative difference for the obtained isotope ratios is only $0.36 \%$. Although the numbers do not all agree within the $1 \sigma$ uncertainties, the precision achieved is considered sufficiently reliable in comparison to the AMS measurements, where typical uncertainties in the range of $\approx \pm 1 \%$ can be reached. The uncertainties of the AMS results are overlapping with both the gravimetric and the MC-ICPMS results. All measurements are compared in Figure 2:

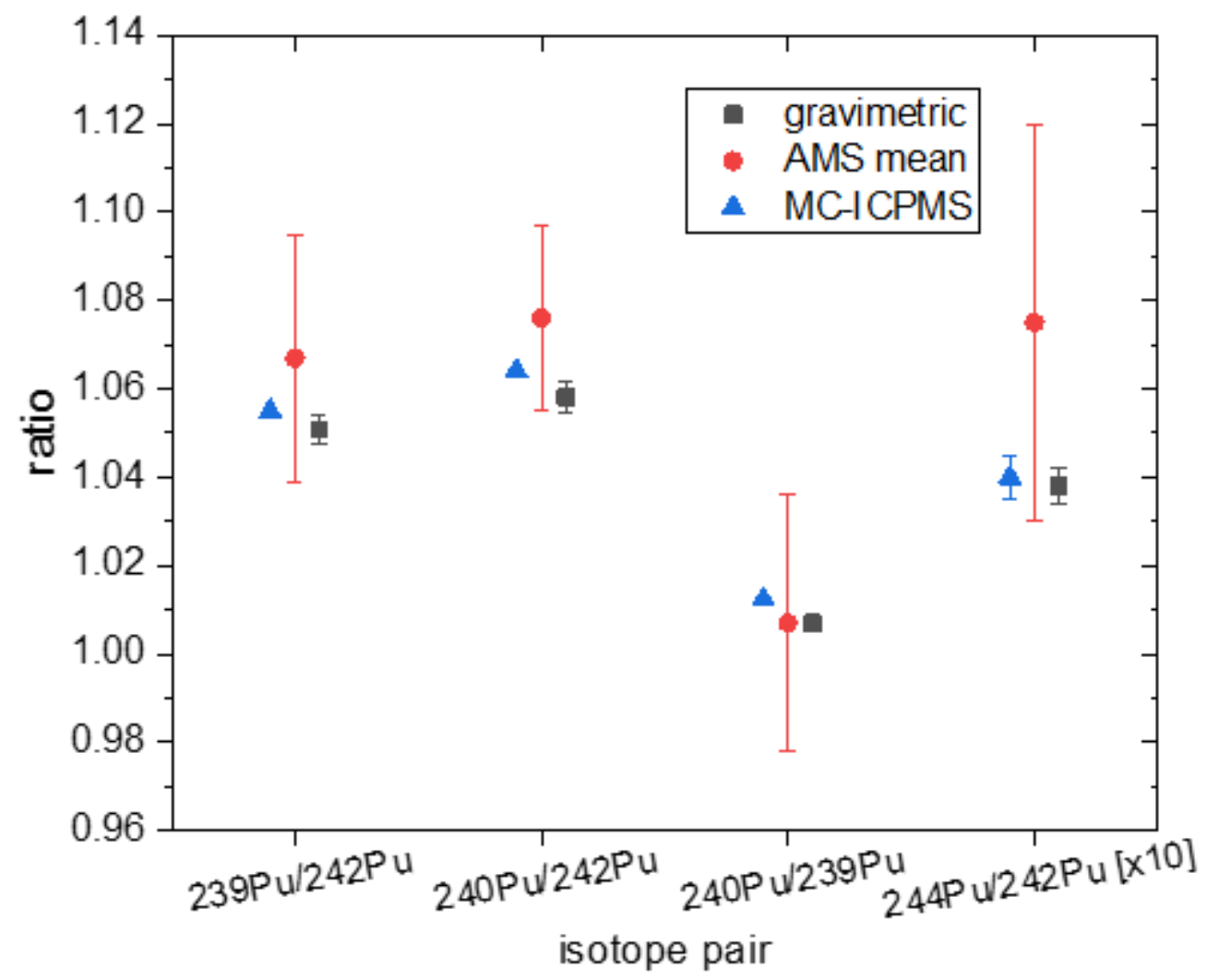

Figure 2: $\mathrm{Pu}$ isotope ratios of the new standard material as calculated from the AMS measurements, MC-ICPMS and gravimetric data, respectively (all $1 \sigma$ uncertainties).

The uncertainties of the three used methods differ more than one order of magnitude. This is mainly due the fact that the overall AMS uncertainty is determined by the stability of the used AMS systems; this is reflected by the fact that the standard error of the mean of all measurements is higher than the individual uncertainties roughly by a factor of 2 . The given 
uncertainties for the MC-ICPMS measurements are even smaller than the uncertainties of the values from gravimetric mixing. This is not surprising, as weighing can - in principle - be considered as the most precise of the three used techniques, but in the special case of weighing solutions with high concentrations of radionuclides, resulting electrostatic effects on the balance have to be mitigated.

Overall, gravimetric, MC-ICPMS and AMS data are consistent within the given uncertainties. However, although the MC-ICPMS measurements have been repeated several times (see supplement), their uncertainty might be slightly underestimated as there was no attempt to measure these values again on a second MC-ICPMS system. The isotope ratios ${ }^{240} \mathrm{Pu} /{ }^{242} \mathrm{Pu}$, ${ }^{240} \mathrm{Pu} /{ }^{239} \mathrm{Pu}$, and ${ }^{244} \mathrm{Pu} /{ }^{242} \mathrm{Pu}$ are consistent within $1 \sigma$ with the gravimetric results, while ${ }^{240} \mathrm{Pu} /{ }^{239} \mathrm{Pu}$ is consistent within $2 \sigma$.

\subsection{Derivation of a consensus value}

To derive a consensus value for the isotope ratios of the new standard material, several approaches were taken into account. Generally, the data from the gravimetric mixing are considered very reliable. The AMS data are in agreement with these values and remarkably consistent with each other, considering they are obtained from very different machines. As expected, the uncertainties of the AMS measurements are the highest of the three methods. The MC-ICPMS data show the smallest uncertainties; however, in contrast to the AMS data, they were obtained only on one distinct machine.

If the consensus value would be derived from a weighted mean of the three methods, it is clear that the small uncertainty of the MC-ICPMS results would dominate the overall uncertainty. However, as this small uncertainty might be slightly underestimated, we decided to calculate the consensus value of the new AMS standard material "ColPuS" (for Cologne Pu Standard) as the equally weighted mean of the gravimetric data, the AMS data and the MC-ICPMS data as given in Table 6 .

\begin{tabular}{|c|c|c|c|c|}
\hline & ${ }^{239} \mathrm{Pu} /{ }^{242} \mathrm{Pu}$ & ${ }^{240} \mathrm{Pu} /{ }^{242} \mathrm{Pu}$ & ${ }^{240} \mathrm{Pu} /{ }^{239} \mathrm{Pu}$ & ${ }^{244} \mathrm{Pu} /{ }^{242} \mathrm{Pu}$ \\
\hline gravimetric & $1.051 \pm 0.003$ & $1.058 \pm 0.003$ & $1.007 \pm 0.001$ & $0.1038 \pm 0.0004$ \\
\hline MC-ICPMS & $1.055 \pm 0.001$ & $1.064 \pm 0.001$ & $1.012 \pm 0.001$ & $0.1040 \pm 0.0001$ \\
\hline AMS (mean) & $1.067 \pm 0.028$ & $1.076 \pm 0.021$ & $1.007 \pm 0.029$ & $0.1075 \pm 0.0045$ \\
\hline $\begin{array}{l}\text { "ColPuS" } \\
\text { Consensus } \\
\text { value }\end{array}$ & $\begin{array}{l}1.058 \pm 0.008 \\
0.80 \%\end{array}$ & $\begin{array}{l}1.066 \pm 0.009 \\
0.83 \%\end{array}$ & $\begin{array}{l}1.009 \pm 0.003 \\
0.27 \%\end{array}$ & $\begin{array}{l}0.1051 \pm 0.0021 \\
2.0 \%\end{array}$ \\
\hline
\end{tabular}


Table 6: Consensus values for the isotopic ratios of the new standard material "ColPuS". The consensus value is the equally weighted mean of the three used methods; the given uncertainty of the consensus value is the standard deviation of the single values from that mean value.

\subsection{Conclusion}

In this work, we have characterized a new Pu-multiisotope standard ColPuS for AMS. The uncertainties of the new standard do not reach the uncertainties of the consumed UKAEA Pu Standard, but they are at least 2 times smaller than the uncertainties of the CNA standard. The new standard is characterized for the isotopes 239, 240, 242, and 244 (the latter is not specified in the CNA standard). The high accordance of the gravimetric and the MC-ICPMS data indicates that is promising to characterize the present standard material further at different MC-ICPMS in the future, with the goal to develop it further into a general standard material with even higher precision.

By including AMS measurements from various institutions into our analysis, we hope to find wide acceptance of the material and the attributed consensus value within the AMS community. There is enough standard material available to produce 200 '000 AMS cathodes, assuming the cathodes are loaded with approx. $5 \mathrm{pg} \mathrm{Pu}$ (per main isotope) which is distributed to interested parties in amounts that are below radiologically defined exemption values.

\section{Acknowledgement}

The authors are grateful for the support of the University of Cologne, in the framework of the emerging group "Uldetis", which made this laboratory intercomparison possible.

\section{References}

M. De Cesare et al.: Actinides AMS at CIRCE in Caserta (Italy), Nucl. Instr. Meth. B, 268 (2010) 779-783.

[2] Chamizo, E. et al.: Determination of the 240Pu/239Pu atomic ratio in soils from Palomares (Spain) by low-energy accelerator mass spectrometry, Nucl. Instr. Meth. B, 249 (2006) 768-771. 
UKAEA, Certified Nuclear Reference Material No.: UK Pu 5/92138, in: H.L. Chemistry Division, Oxfordshire OX11 ORA. and reference materials, Nucl. Instr. Meth. B, 294 (2013) 29-38.

[6] M. Paul et al.: Experimental limit to interstellar ${ }^{244} \mathrm{Pu}$ abundance, The Astrophysical Journal, 558, (2001) 133-135.

A. Wallner et al.: Abundance of live ${ }^{244} \mathrm{Pu}$ in deep-sea reservoirs on Earth points to rarity of actinide nucleosynthesis, Nat. Commun. 6, (2015) 5956.

K. Hotokezaka et al.: Short-lived ${ }^{244} \mathrm{Pu}$ Points to Compact Binary Mergers as Sites for Heavy r-process Nucleosynthesis, Nat. Phys., 11, (2015) 1042-1044.

B.-A. Dittmann et al.: Preparation of a multi-isotope plutonium AMS standard and preliminary results of a first inter-lab comparison, Nucl. Instr. Meth. B, 361, (2015) 327-331.

E. Chamizo et al.: Plutonium measurements on the 1 MV AMS system at the Centro Nacional de Aceleradores (CNA), Nucl. Instr. Meth. B, 266 (2008) 4948-4954.

M. De Cesare et al.: Actinides AMS at CIRCE and ${ }^{236} \mathrm{U}$ and Pu measurements of structural and environmental samples from in and around mothballed nuclear power plant, Nucl. Instr. Meth. B, 294 (2013) 152-159.

S. Richter et al.: New average values for the $n\left({ }^{238} \mathrm{U}\right) / \mathrm{n}\left({ }^{235} \mathrm{U}\right)$ isotope ratios of natural uranium standards, Int. J. Mass. Spec., 295, (2010) 9497. 
A. Dewald et al.: The first year of operation of CologneAMS; performance and developments, EPJ Web of Conferences, 63 (2013) 03006.

[14] L.K. Fifield et al.: Accelerator mass spectrometry of plutonium isotopes, Nucl. Instr. Meth. B, 117 (1996) 295-303. 


\section{Supplemental data}

MC-ICPMS measurements

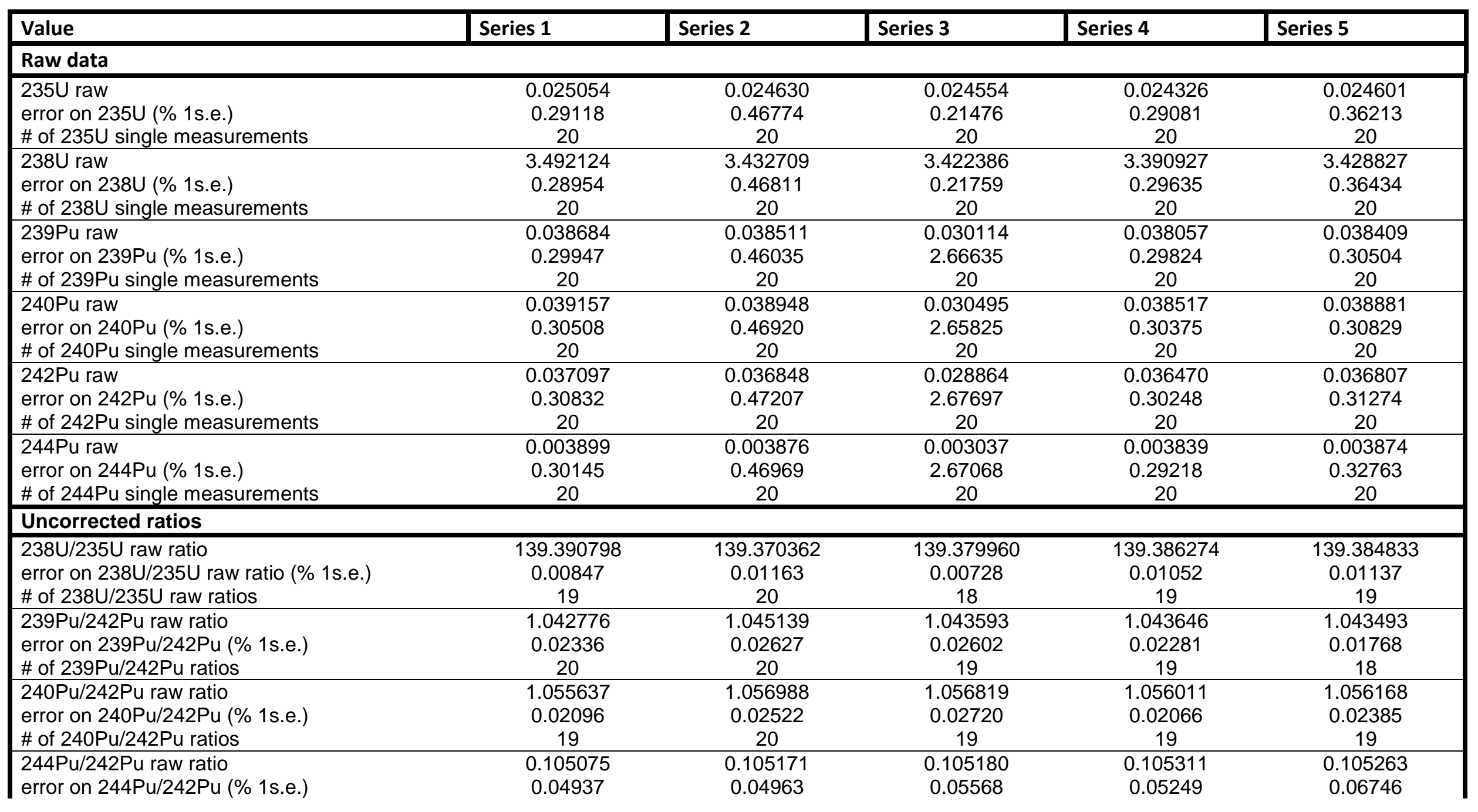


\# of 244Pu/242Pu ratios 19

19

Mass bias corrected ratios

$238 \mathrm{U} / 235 \mathrm{U}$ ratio

error on $238 \mathrm{U} / 235 \mathrm{U}$ ratio (\% 1s.e.)

137.837

0.015

19

\# of $238 \mathrm{U} / 235 \mathrm{U}$ ratios

239Pu/242Pu ratio

error on $239 \mathrm{Pu} / 242 \mathrm{Pu}$ (\% 1s.e.)

1.05426

0.02698

20

240Pu/242Pu ratio

1.06325
0.02457

20

error on 240Pu/242Pu (\% 1s.e.)

\# of 240Pu/242Pu ratios

244Pu/242Pu ratio

0.10432

error on 244Pu/242Pu (\% 1s.e.)

0.05004

19

240Pu/238U

0.01127
0.246382

error on $240 \mathrm{Pu} / 238 \mathrm{U}$ (\% 1s.e.)

18

137.837

19

19

20

\# of $240 \mathrm{Pu} / 238 \mathrm{U}$ ratios

0.015

20

1.05655

0.02999

20

1.06465

0.02859

20

0.10445

0.05446

20

0.01135

0.053720

19

$\begin{array}{lc}137.837 & 137.837 \\ 0.015 & 0.015\end{array}$

19

18

19

1.05505

0.03097

19

1.05493

19

1.06452

0.03001

1.06388

0.01907

18

0.10443

0.10455

0.05813
19

0.05299

0.00892

19

2.788799

0.01135

20

19

137.837

0.015

19

1.05495

0.02449

20

1.06390

0.02483

19

0.10451

0.07137

20

01134

20 